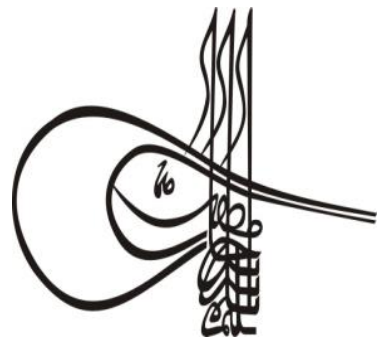

Received/Geliş: 12.07 .2019

\section{Turkísh Studies}

Volume 14 Issue 4, 2019, p. 2779-2795

DOI: 10.29228/TurkishStudies.23509

ISSN: 1308-2140

Skopje/MACEDONIA-Ankara/TURKEY

Research Article / Araștırma Makalesi

Article Info/Makale Bilgisi

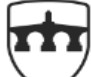

INTERNATIONAL BALKAN UNIVERSITY

EXCELLENCE FOR THE FUTUR IBU.EDU.MK

$\checkmark$ Accepted/Kabul: 10.08 .2019

Go Report Dates/Rapor Tarihleri: Referee 1 (22.07.2019)-Referee 2 (28.07.2019)

This article was checked by iThenticate.

\title{
GAZİ ÜNİVERSİTESİ DİPLOMASI, ARMASI VE İMGESEL TASARIM ÖGELERİ
}

\author{
Abbas KETIZZMEN*
}

\section{öz}

Diploma bir eğitim sürecinin başarıyla tamamlandığını belgeleyen en önemli evraktır.

Gazi Üniversitesi Diplomalarının yeniden tasarlanmasına 1996 yılında, dönemin rektörü ${ }^{1}$ tarafından karar verildi. Dört akademisyen tasarımcı seçildi ve çalıșmalarına bașlandı. 4 yıl devam eden süreçte uygun sonuç elde edilemedi. 2000 yılında seçilen rektör ${ }^{2}$ tarafından aynı talep tekrar edildi. Sürecin, yine olumsuz sonuçlanması üzerine, 2001 yılında diploma tasarımı için, araştırmacı akademisyen-grafik tasarımcidan ${ }^{3}$, tasarım talebinde bulunuldu.

Gazi Üniversitesi, diploma tasarımları ile bir ilk yaratmaya, kurumsal tanıtımına örnek olmaya önem verdi. Tasarımcının yaptığı yüzlerce tasarımı defalarca üniversite senatosunda görüşüldü. Hazırlamış olduğu "Gazi Üniversitesi Arması" büyük beğeni gördü. Arma, diplomanın en önemli görsel unsuru olarak kabul edildi.

Gazi Üniversitesi Arması, bünyesinde bulunan on dokuz akademik birimin her biri için fakültelerin eğitim alanlarıyla ilgili imgesel tasarımının, simgesel ve soyut yorumlarıyla oluşturuldu. Logo tarzındaki bu simgesel tasarımlar, fakültelerin logo tasarımı olarak ta değerlendirilmek üzere incelendi. Her biri, yüzlerce çalışma ve onlarca sunum sonucu kabul edildi. Bu simgelerden Tip alanı ile ilgili olanı Gazi Üniversitesi, Tip Fakültesi tarafından onbeş yıl boyunca Gazi Üniversitesi Tıp Fakültesi ve Hastanesi logosu olarak kullanıldı. Ayrıca, Gazi Üniversitesi Armasını oluşturan "mesleki alan simgeleri" arma ile birlikte her fakültenin özgün sembolleri olarak ta kendi diplomalarında

${ }^{2}$ Prof. Dr. Riza Ayhan

${ }^{3}$ Doç. Dr. Abbas Ketizmen 
kullanıld1. Arma, her y1l 15-20 bin civarında mezun veren Gazi Üniversitesi'nin diplomalarında 13 yıl boyunca yer aldı.

Gazi Üniversitesi, armada, çevresindeki on dokuz yıldızın birleşiminden oluşan "Şems"(Güneş) motifi ile sembolize edilmiştir. Güneşin etrafını oluşturan ve her biri ayrı ayrı fakültelerin imgelerini çevreleyen on dokuz yıldız simgesi tasarımında, Selçuklu bezemelerinden (motiflerinden) esinlenilmiştir ve kuyruklu yıldızı ifade etmektedir.

Gazi Üniversitesi Armas1, çoğu alanlarda saç k1lı inceliğinde olmak üzere tamamen vektörel formda hazırlanmış ve (kıymetli kağıt baskı tekniğinde kullanılan yöntemler gibi) klişe-tipografi yöntemiyle basılmıștır. Böylece, Gazi Üniversitesi'nin yeni diplomaları güvenlik özellikli ilk ve tek diploma haline geldi.

Anahtar Kelimeler: Gazi Üniversitesi Diplomas1, Tasarım, Arma, Logo ve Fors

\title{
GAZI UNIVERSITY DIPLOMA, SEAL AND IMAGERY DESIGN ELEMENTS
}

\begin{abstract}
A diploma is the most significant document proving successful completion of an educational phase.

In the year 1996, the Rector of Gazi University at that time ${ }^{4}$, requested a redesign of Gazi University diplomas. Four designer faculty members were selected and commenced their studies. At the end of a four year process, a satisfactory result could not be produced. In the year 2000, the next Rector ${ }^{5}$ of the university requested the same study. Following another failed process, a design was requested from an academician and graphic designer ${ }^{6}$ in 2001.

It was Gazi University's priority to be a pioneer and provide an example of corporate promotion through its diploma design. Hundreds of designs made by designer were discussed several times by the university senate. The "Gazi University Seal" he designed was widely appreciated. The seal was approved as the most significant visual element of the diploma.

Gazi University Seal was created through symbolic and abstract interpretation of imagery design relevant to educational fields of faculties for each of all 19 academic units. These imagery designs in the form of a logo were studied to be evaluated as the logo design for faculties. Each of the designs were approved following hundreds of work pieces and dozens of presentations. The symbol related to medicine was used by Gazi University, Faculty of Medicine for fifteen years as Gazi University Faculty of Medicine and Hospital logo. In addition, "vocational field symbols" constituting the Gazi University Seal were used together with original
\end{abstract}

\footnotetext{
${ }^{4}$ Prof. Dr. Enver Hasanoğlu

${ }^{5}$ Prof. Dr. Riza Ayhan

${ }^{6}$ Doç. Dr. Abbas Ketizmen
} 
symbols of individual faculties on relevant diplomas. For thirteen years, the seal appeared on Gazi University diplomas, received annually by fifteen to twentythousand graduates.

Gazi University is symbolized by the "Shams" ("the Sun")pattern formed of nineteen stars around the armada. The nineteen stars design surrounding symbols of individual faculties, making up the Sun, was inspired by Selcuklu motifs and is an expression of a comet.

Gazi University Seal was developed in the form of fully vectoral form mostly as thick as a strand of hair and printed by line engravingtypography method (such as the methods used in valuable paper printing). Thus, The new diplomas of Gazi University has become first and only diplomas with security features.

\section{STRUCTURED ABSTRACT}

Viewed historically, today, it is possible for us to see symbols such as widely used signs in various forms and designations such as emblems, logos, logo types, badges or flags. Their most popular version in the past was the type called badge.

Turkish Language Association's definition of the word badge is: "A drawing, a letter or a shape that is accepted as the symbol of a country, a dynasty or a city"(TDK, 2009).

Badge and symbol designs commonly observed in contemporary western nations can be observed in history as professional designs in flags and pennants of Asian civilizations.

An analysis of such designs would indicate that prominent legends regarding existence of the relevant society, mythological stories and imagery are symbolized.

The meaning of the word "mythology" (mythologia) is science of legends. Erhat, claim that; Each society have distinctive mythologies of their own and they act as a mirror of the society they represent. (Erhat, 1972)

It is a fact that, interest towards symbols is not limited only to patterns and that they are used as means of representation in various forms and ways as part of religions.

A look at history would reveal that symbols were always used widely in religious narratives. Symbolism plays an important role in people's religious lives (Atasağun, 2001:126).

Seal designs rich with symbols and signs of the past are now replaced with more simplified and abstracted logo designs. In our country, despite a tradition of carrying a badge even at elementary schools in the first century of the Republic, this tradition is observed to have been abandoned in the years that followed. In our contemporary world, the tradition of use of badges especially in the western countries constitutes an essential element of corporate identity. In Europe, we can see a contentful badge and flag of each city reflecting the distinctive characteristics and riches of said city. 
Use of badges is especially common in the western countries. Universities use original badges in their diplomas to add visual richness and image. However, use of badges in our universities is still absent. Other than the limited number of badges used at the time of the Ottoman Empire, the only known badge used is the badge that constitutes the Presidential Seal. In Turkish and Islamic culture similar designs are available in various forms especially in the art of illumination.

Universities' positive perception by the society is an indication of their corporate strength. However, it is of utmost importance to support such corporate character visually.

As corporate promotion became important for Gazi University, the preliminary step taken was to redesign its diplomas. Previous version of Gazi University diplomas had an unprofessional and unimpressive design. In addition to their weak design, protection against forgery was almost nonexistent.

As a first step, a seal (badge) design was developed for Gazi University to ensure visual richness of diplomas.

In the year 1996, the Rector of Gazi University at that time ${ }^{7}$, requested a redesign of Gazi University diplomas. Four designer faculty members were selected and commenced their studies. At the end of a four year process, a satisfactory result could not be produced. In the year 2000 , the next Rector ${ }^{8}$ of the university requested the same study.Following another failed process, a design was requested from an academician and graphic designer ${ }^{9}$ in 2001.

It was Gazi University's priority to be a pioneer and provide an example of corporate promotion through its diploma design. Hundreds of designs made by designer were discussed several times by the university senate. The "Gazi University Seal" he designed was widely appreciated. The seal was approved as the most significant visual element of the diploma.

Gazi University Seal was created through symbolic and abstract interpretation of imagery design relevant to educational fields of faculties for each of all 19 academic units. These imagery designs in the form of a logo were studied to be evaluated as the logo design for faculties. Each of the designs were approved following hundreds of work pieces and dozens of presentations. The symbol related to medicine was used by Gazi University, Faculty of Medicine for fifteen years as Gazi University Faculty of Medicine and Hospital logo. In addition, "vocational field symbols" constituting the Gazi University Seal were used together with original symbols of individual faculties on relevant diplomas. For thirteen years, the seal appeared on Gazi University diplomas, received annually by fifteen to twentythousand graduates.

Gazi University is symbolized by the "Shams" ("the Sun")pattern formed of nineteen stars around the armada. The nineteen stars design surrounding symbols of individual faculties, making up the Sun, was inspired by Selcuklu motifs and is an expression of a comet.

${ }^{7}$ Prof. Dr. Enver Hasanoğlu

${ }^{8}$ Prof. Dr. Riza Ayhan

${ }^{9}$ Doç. Dr. Abbas Ketizmen 
The Rectorate Building in the middle was recreated applying vectoral technique, similar to the creation of the seal in the past. In its design, water colored architectural drawing scale of the Rectorate Building, originally created by Architect Mimar Kemalettin was adhered to. The spiral form of the series of faculty names surrounding the building represents stepping forward for new horizons.

The Gazi University Seal is an interpretation of Shams. The Surah Ash-Shams in the holy Quran starts with: "By the Sun and his (glorious) splendor...".The leaf pattern decorating both sides of the Gazi University $\mathrm{S}$ is an interpretation of Simurgh. This mythological creature is known in the eastern culture as Simurgh and in the western culture as Phoenix, and is depicted as living on an all-healing tree, as being reborn from its ashes. It represents wisdom and resurrection; just like our Republic and War Veteran (Gazi) Mustafa Kemal as well as Gazi University rising like a torch in Anatolia upon his signature.

A total of 37 Gazi University Seal varieties of the same style but varying elements have been designed to be used on bachelor's, master's and doctorate diplomas as well as other such documents for all its Institutes, Faculties and Colleges, each symbolized with their unique logos.

Gazi University Seal was developed in the form of fully vectoral form mostly as thick as a strand of hair and printed by line engravingtypography method (such as the methods used in valuable paper printing). Thus, The new diplomas of Gazi University has become first and only diplomas with security features.

Gazi University Seal and visual design of Gazi University diplomas identified with the Seal have been selected from thousands of design works created in a five-year design process were found to be satisfactory by the administrators of the time and thus, diplomas were printed and used for thirteen years.

All diplomas awarded by Gazi University were uniquely prepared by Mr. Ketizmen through many years of visual design work, research and experimental studies and upon countless presentations to the Senate. This process constituted Ketizmen's dissertation topic. An examined patent, a scientific research project and an article has been created based on his dissertation. Gazi University Seal and diploma images as well as security features were introduced, however limitedly, in his dissertation.

Keywords: Gazi Üniversity, Design, Logo, Seal Logo, Badge,

\section{Giriş}

Tarihi süreç içerisinde incelendiğinde günümüzde yaygın olarak kullanılmakta olan simge türü sembolleri, amblem, logo, logotype, arma, fors gibi farklı biçimlerde ve adlandırabileceğimiz şekillerde görebilmekteyiz. Geçmişte en yaygın ve bilinen türleri ise arma olarak kullanılan türleridir.

Türk dil kurumu sözlüğünde arma; "Bir devletin, bir hanedanın veya bir şehrin simgesi olarak kabul edilmiş resim, harf veya şekil," olarak ifade edilmektedir (TDK, 2009). 
$\mathrm{Bu}$ gün hali hazırda batı toplumunda yaygın olarak kullanılmakta olan sembol tasarımlarını, tarihteki Asya uygarlıklarının bayrak ve forslarında armaları olarak profesyonel tasarımlar halinde görülmektedir.

$\mathrm{Bu}$ tasarımlarda, toplumun varlığında önemli yer tutan efsaneleri, mitolojik öyküleri ve imgelerin, simgesel olarak sembolize edildiği, incelendiğinde ortaya çıkmaktadır.

Mitoloji (mythologia) sözcüğü, efsaneler bilimi anlamına gelmektedir. Erhat'ın açıklamalarına göre, her toplumun kendine özgü bir mitolojisi vardır ve bu mitolojiler temsil ettiği topluluğun aynası gibidir (Erhat, 1972).

Buna en güncel örneği verecek olursak, geçmişte Türk Devletlerinin bayraklarının süsleyen ejder sembolünü (Büyük Hun İmparatorluğu bayrağında) bu gün batı ülkelerinde özellikle Avrupa da hâlâ zengin tasarımlar biçiminde bayrakları, armaları veya sembolleri içinde yer almaktadır.

Sembollerin inanç dünyasında da farklı biçim ve şekillerde betimleme aracı olarak kullanıldığ bilinmektedir.

Tarihe baktığımızda dinî anlatımda her zaman sembollerin yaygın olarak kullanıldığın görürüz. Sembolizm insanların dinî hayatında önemli bir rol oynamaktadır(Atasağun, 2001).

Uygarlık tarihinde, sembollerin önemli bir ifade unsuru olduğu bilinmektedir.

Schimmel'e göre; büyük sembol gruplarına Eski Mısır ve Mezopotamya'da çok daha sık rastlanır. Yunan-Roma dünyasında olduğu kadar ilkel ve arkaik dinlerde de sembole oldukça geniş yer verildiğini görmekteyiz(Schimmel,1954:70).

Armaların sadeleşmiş ve yalın anlatımlı görsel elemanlarını oluşturan sembollerin taşıdığı anlam önemlidir. Schimmel'in yorumuyla anlam derinliğine bakacak olursak; "Hakiki sembol, görülen bir surette görülmeyen bir hakikata işaret eder ve ruhun derinliğine, şuur altındaki sahalarına kadar tesirler bırakıp bir çok fikir ve duyguları uyandıracak kadar kuvvetlidir. Sembolde kutsal bir hakikat mevcut olduğundan sembol de kutsal olanın iki tarafına heybet ve korku, uyandıran celalı ile hayranlık ve zevk bahşeden cemalı ihtiva etmektedir. Sembolün çözülmeyecek muamması, esrarengiz tarafı budur" (Schimmel,1954:70).

Türk devletlerinin bayraklarında yer alan sembolleri yukarıdaki yaklaşımlarla incelediğimizde bu anlatıma yakışan en güzel örnekler olarak tanımlayabiliriz.

Tarihsel süreçten günümüz dünyasına gelindiğinde sembol, arma kültürünün günümüzde amblem, logo, logotype gibi sadeleştirilerek çok daha geniş platformlarda özellikle reklam ve tanıtım sektörünün vazgeçilmez unsuru olarak kullanıldığını görmekteyiz. Günümüz dünyasında simgeleşen imgeler, logolara dönüşmüş ve kurumsal kimliğin vazgeçilmez imaj unsuru haline gelmiştir.

Amblem, farklı ve hatırlanabilir bir görsel kimlik yaratmak için logo ile birlikte kullanılan semboldür. Amblem bir sembol olarak ifade edilirken, logo markanın sembol ile bütünleştirilmesiyle oluşmaktadır (Aaker 1991:198). Amblem bir kurumu anlatan simgedir. Hedef kitleye o kuruluşun karakteri, çalışma alanı görüntüsü, hizmet anlayışı, felsefesi, boyutları, kalitesi ve başarıları hakkında bilgi vermektedir (Çoroğlu, 2002:116).

$\mathrm{Bu}$ bağlamda kurumların kuruluş aşamasından başlayarak, uluslararası platformda kendilerini anlatmak için kullandıkları görsel kimlik unsurlarından olan amblem ve logo tasarımlarının niteliğinin, "akılda kalıcılık" ve "süreklilik" oluşturması açısından incelenmesi gerekmektedir. Akılda kalıcıllı̆ın ve sürekliliğin göstergesi olarak kimi kurumların logoları nın her geçen gün ikonlaşması küreselleşmenin evrensel boyuttaki göstergesidir. Dolayısıyla kurumların evrensel boyutta bir tanınırlığının oluşabilmesi için anlaşılır, akılda kalıcı ve süreklilik sunan göstergelere gereksinim duyulmaktadır (Bayraktaroğlu ve Çalış, 2010:5-7). 
Bir markaya ait kimlik, tüketicilerin seçimleri üzerinde etken olan ve bu markanın belleklerde yer edinerek diğerleri arasında ayırt edilebilir olmasını sağlayan önemli unsurlardan biri olarak belirmektedir. "Marka kimliğii" olarak nitelenen bu kavramı, belirli bir isim veya markaya ait imge, görsel bir sembol/sembolleri veya çağrışım nesnesi/nesneleri arasında kurulan ortak, özgün görsel dil ve bunun zihinlerde yarattığı etki olarak nitelendirmek mümkündür. Görsel kimlik yaratmak, temel işlevi, yaratıcı estetik kullanım nesneleri ortaya koymak olan tasarımın gerçekleştirebileceği bir yetidir. $\mathrm{Bu}$ çerçevede ele alınacak konu kimlik yaratma gücü bulunan tasarım ve bu gücün doğru kullanılmasını sağlayan yönetim faaliyetlerinin, görsel kimlik olarak algılanabilecek bir oluşum yaratmadaki etkileri üzerinedir (Pringle, 2000:52)

Kurum kimliği unsurlarından biri olan logolar ise, kurum ya da markanın görünen gücü olarak tanımlanabilir. Bu güç, kurum ya da markanın müşteriye verdiği güvencenin bir göstergesidir. Ancak bazen işletmeler logolarını değiştirebilmektedir. Özellikle bilinen bir kurum logosunu değiştirdiğinde bu, kurum kimliğini etkilemektedir (Öztürk, 2006). Logo ve amblem tasarımı marka, işletme, ürün kimliğini ifade eden ve akılda kalıcılığı sağlayan en etkili araçlardan biridir. Akılda kalıcılığı sağlama konusunda görsel hafızanın, işitsel ve sesli hafızadan çok daha etkili olduğu bilinmektedir (Çakır, 2013). Kurum felsefesinin göstergesi olan kimlik tasarımının, görsel olarak biçimlenmesinin oldukça önemli olduğunu ve görsel kimliğin kolay algılanabilir olmasının gerekliliği karşımıza çıkarmaktadır (Bayraktaroğlu ve Çalış, 2010:5-7).

Sembollerin resmediliş şekli itibariyle amblemden logoya dönüşümüne ait iki çarpıcı örnek aşağıda verilmiştir.

Tarihte yapılan ilk kurumsal kimlik çalışmalarından biri olan AEG (Allgemeine ElektrizitätsGesellschaft) için tasarlanan logo, Otto Eckmann tarafından 1899 yılında yapılmıştır. 1908 ve 1912 yıllarında Peter Behrens logoyu gözden geçirerek düzeltmeler yapmış, logo gittikçe yalına indirgenmiştir (Demir, 2006:49-51).
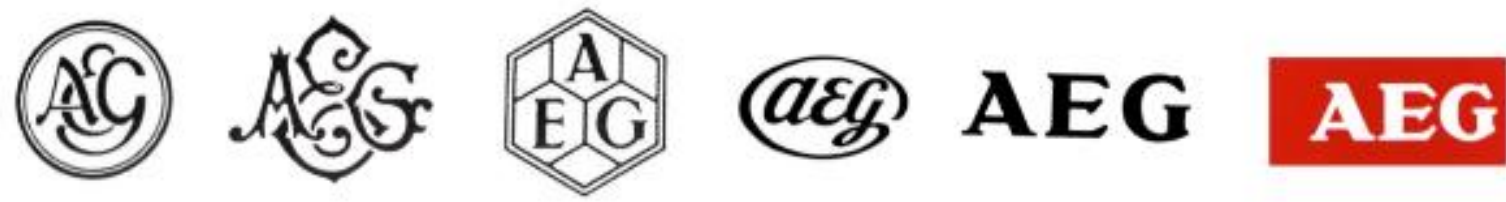

Şekil 1: AEG logosunun zaman içerisindeki değişiminden örnekler (www.underconsideration.com/brandnew/archives/aeg_logo_evolution.jpg)

Pelikan markasının logosu da birçok kez yenilenmiştir. 32 yıldır kuruluşun amblemi olarak kullanılan arma, 1910 yılında E. W. Baule tarafından sadeleştirilerek günümüz Pelikan kurumsalının temelini oluşturmuştur. 1938'de ise Hadan, piktografik bir tasarımla amblemi yeniden yorumlamışır (Demir, 2006:49-51).

\section{Pelikan}
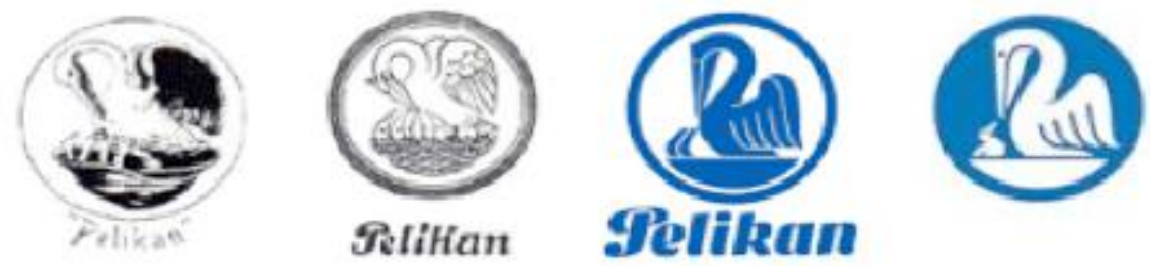

Şekil 2: Penpedia'dan bir alıntı: Pelikan Logosunun zaman içinde değişimi (Bayraktaroğlu ve Çalış, 2010) 
Arma kullanımı özellikle batılı ülkelerde çok yaygındır. Serbest piyasa ekonomisi ile dünya pazarlarında yerini alan Türkiye'de kurumsal kimlik çalışmalarına baştan beri çok önem verildiği, tanıtım mecralarındaki tasarımlardan anlaşılmaktadır. Başta resmi kuruluşlar olmak üzere kurumsal amblem ve logo tasarımı olmayan resmi ve tüzel kuruluş nerdeyse yok denecek kadar azdır.

Ancak, sadeleştirilmiş amblem ve logonun dışında arma türü zengin içerikler ve görselliklere haiz tasarımlara nadiren rastlanılmaktadır.

Geçmişte kullanılan zenginleştirilmiş sembol ve simgelerden oluşan arma tasarımı günümüzde eskisi kadar kullanım alanı bulamaz hale gelmiştir. Cumhuriyetin ilk yıllarında neredeyse her ilkokulun dahi bir arması var iken sonraki yıllarda bu gelenek tamamen yok edilir hale gelmiştir. Günümüz dünyasında, özellikle batı ülkelerinde halen devam eden arma kullanım geleneğini, kurumsal kimliğin vazgeçilmez ögelerinden biri olarak, çok zengin tasarımlarla görebilmekteyiz. Batı ülkelerinde birçok şehrin dahi kendine ait bir arması vardır. Bu arma o şehrin, kasabanın veya o bölgeye ait bir kurum var ise onun gücünü temsil eder, ona bir köklü geçmiş imajı kazandırır. Tasarım içeriğindeki zenginliği ile ilgili semboller ve figürler taşır. Bu yaklaşım, eğitim kurumlarına da yansımış, tanıtım gücünü yansıtan armalar ve forslar olarak birçok okullarının diplomalarında logolarıyla birlikte yer almıştır. Bu tür tasarımlar görselliği etkileyen ve imajı güçlendiren unsurlar olmuştur.

Üniversitelerin de kurumsal gücünün en iyi ve en yaygın tanıtımı şüphesiz o kurumun sektördeki pozitif yansımalarıdır. Ancak bu kurumsallığın görsel olarak desteklenmesi ise son derece önemlidir. Üniversiteler diplomalarında görsel zenginlik ve imaj katan özgün armalar kullanmaktadır. Ancak ülkemiz üniversitelerinde arma kullanımı hali hazırda görülmemektedir. Osmanlı İmparatorluğunda kullanılan sınırlı sayıdaki armaların dışında tek bilinen Türkiye Cumhurbaşkanlığı Forsu'nu oluşturan armadır. Türk ve İslam kültüründe benzer tasarımlar ise, özellikle tezhip sanatında görülen farklı biçimlerdeki "Şems" tasarımlarıdır. Türk dünyası ve islam ülkelerinde bu tür sembolleri daha çok bezeme biçimiyle süsleme sanatında da görmekteyiz. Ülkemiz coğrafyasında ise geçmişten devam eden gelenekleriyle, özellikle şems biçimindeki (güneş) sembol ve süslemeleri, tezhip sanatında kitap kapaklarında ve halı, kilim, oymacılık, mimari yapı elemanları gibi süsleme sanatında yaygın olarak bulabilmekteyiz.

Diploma bir eğitim sürecinin başarıyla tamamlandığını belgeleyen en önemli evraktır Gazi üniversitesi de kurumsal tanıtıma önem verdiğinde ilk olarak diplomalarını yeniden tasarlamayla süreci başlatmıştır.

Gazi Üniversitesi diplomalarının yeniden tasarlanmasına 1996 yılında, dönemin rektörü ${ }^{10}$ tarafından karar verildi. Dört akademisyen tasarımcı seçildi ve çalışmalarına başlandı. Dört yıl devam eden süreçte uygun sonuç elde edilemedi. 2000 yılında seçilen rektör ${ }^{11}$ tarafından aynı talep tekrar edildi. Sürecin, yine olumsuz sonuçlanması üzerine, 2001 yılında diploma tasarımı için, araştırmacı akademisyen-grafik tasarımcidan ${ }^{12}$, tasarım talebinde bulunuldu.

Gazi Üniversitesi, diploma tasarımları ile bir ilk yaratmaya, kurumsal tanıtımına örnek olmaya önem verdi. Tasarımcının yaptığı yüzlerce tasarımı defalarca üniversite senatosunda görüşüldü. Hazırlamış olduğu “Gazi Üniversitesi Arması" büyük beğeni gördü. Arma, diplomanın en önemli görsel unsuru olarak kabul edildi.

\footnotetext{
${ }^{10}$ Prof. Dr. Enver Hasanoğlu

${ }^{11}$ Prof. Dr. Riza Ayhan

${ }^{12}$ Doç. Dr. Abbas Ketizmen
} 
Şekil 3: Gazi Üniversitesi Arması, (Ketizmen, 2008, S: 176)

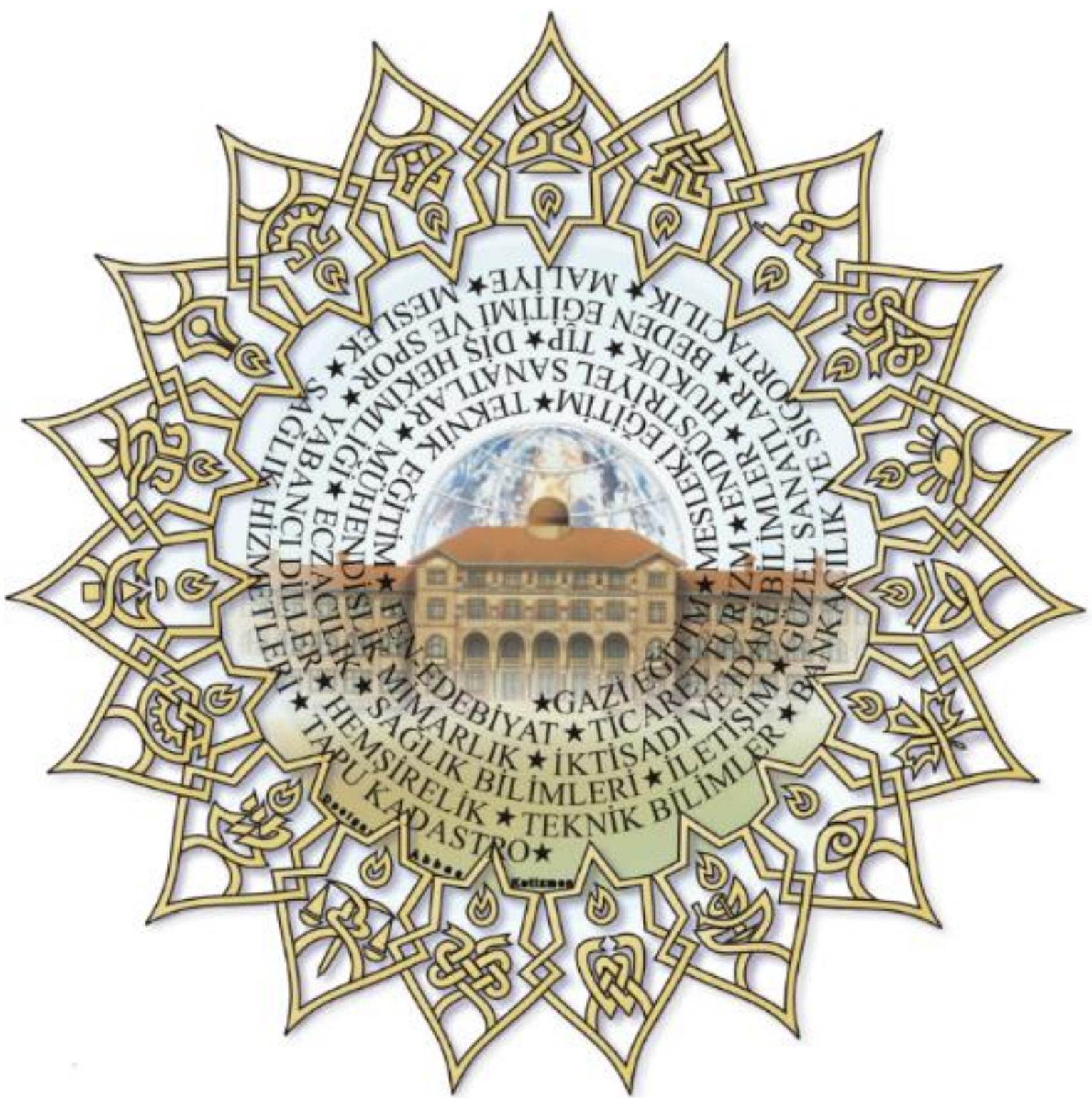

Makale konusu olan Gazi üniversitesi armasının tasarımında ve sembollerin oluşturulmasında, kültürel değerler, yaklaşımlar değerlendirilerek yola çıkılmıştır.

Gazi Üniversitesi arması, çevresindeki on dokuz yıldızla "Güneş" (Şems) motifi olarak sembolize edilmiştir. Güneşin etrafını oluşturan ve fakültelerin imgelerini çevreleyen on dokuz simgeleştirilmiş yıldız, kuyruklu yıldızı sembolize etmekte olup içerisinde akademik alanlardan her birinin logosunu taşımaktadır. Üniversite bünyesindeki tüm fakülte, enstitü ve yüksek okulları için onları sembolize eden ve her biri diğerinden farklı nitelikte ayrıştırıcı on dokuz farklı logo tasarlanmış, farklı özellik taşıyan bu logolar Selçuklu bezemelerini çağrıştıran on dokuz adet yıldız tasarımıyla bütünleşerek bir güneş formunu oluşturmuştur. Biçimler arasındaki boşluklar ve bağlayıcı çizgiler bilimsel düşüncenin bütünlügünü ve disiplinler arası ilişkilerin önemini vurgulamaktadır. 
Gazi Üniversitesi için hazırlanan (Şekil-3) arma tasarımında kültürel değerlerimiz ve tasarım tarzımız ön planda tutulmuştur. $\mathrm{Bu}$ nedenle Gazi Üniversitesi armasına gören bir kişinin T.C. Cumhurbaşkanlığı armasını hatırlaması beklenen durumdur. İçerik ve tarz olarak her ne kadar farklı armalar olsalar da, geometrik form açısından benzerliğiyle ortak kültür değeri yakalanmaya çalışılmıştır. Cumhurbaşkanlığı arması incelendiğinde, ortak benzer değerlere sadık kalındığı görülecektir. Tasarımdaki bu yaklaşımın ilk görüldüğünde ülke imajını çağrıştırması yönüyle etkili olacağı varsayımı da düşünülmüştür. Türkiye Cumhuriyeti Cumhurbaşkanlığının forsunu oluşturan armasında, ortasında sekiz uzun, sekiz kısa 1şını olan güneş ve çevresindeki onaltı yıldızdan oluşan şekil incelendiğinde, (Cumhurbaşkanlığ 1 resmi web sitesinde açıklandığı gibi) güneş sonsuzluğu ve bu özelliği ile Türkiye Cumhuriyeti'ni temsil etmekte, onaltı yıldız ise tarihteki bağımsız onaltı büyük Türk Devletini simgelemektedir. Arma, Cumhurbaşkanlığının Amblemi niteliğindedir (https://www.tccb.gov.tr/cumhurbaskanligi/ resmi-simgeler/arma/).

Gazi Üniversitesi armasını oluşturan yıldız biçimindeki on dokuz sembolün her birinin içerisinde ise, on dokuz akademik birimin imgesel tasarımının simgesel soyut yorumu logo halinde tasarlanmıştır. Tasarımında Selçuklu bezemelerinden esinlenilmiştir. Gazi Üniversitesi logosunu özel kılan tasarım ögeleri bunlardır. Gazi Üniversitesi armasının, ortasındaki rektörlük binası, (armanın hazırlandığ 1 gibi) tamamen vektörel teknikle yeniden hazırlanmıştır. Tasarımında orjinali Mimar Kemalettin'e ait olan rektörlük binası suluboya mimari resminin ölçeğine sadık kalınılmıştır. Armanın ortasında bulunan vektörel hazırlanmış rektörük binasının etrafını çevreleyen fakülte isimleri dizini ise, spiral formu ile evrenselliği ve yeni ufuklara açılımı temsil etmektedir.

Armanın renk seçiminde de araştırma ve deneysel çalışmalar yapılmıştır. Ceylan, 2015 yılında yayınladığı araştırma makalesinde, amblem, logo veya logotype tasarımlarında, renklerin doğru tercihlerinin akılda kalıcılı̆̆ artırırken mesaj verebildiklerini savunmaktadır (Ceylan, 2015). Yapılan değerlendirmeler sonucu, kurumsal gücün temsili yönüyle arma tasarımında sarı renk (Altın rengi) tercih edilmiştir.

Armayı oluşturan logo tarzındaki sembollerin tasarımları, aynı zamanda fakültelerin logo tasarımı olarak ta değerlendirilmek üzere üniversite senatosunda yapılan sunumlarda incelenmiştir. Her bir sembol yüzlerce çalışma ve onlarca sunum sonucu kabul edilmiştir. Bu simgelerden Tıp alanı ile ilgili olanı, Gazi Üniversitesi Tıp Fakültesi tarafından onbeş yıl boyunca "Gazi Üniversitesi Tip Fakültesi Logosu” olarak kullanılmış ve hastanesi logosu olarak ta kullanılmaktadır.

Gazi Üniversitesi, Tıp Fakültesinin talebiyle, Ketizmen tarafından hazırlanan 80 adet gazi tıp logo tasarımından onaltı adedi tıp fakültesi hocalarının oyuna sunulmuş, internet üzerinde oylama sonucu seçilen bu günkü logosu kullanılmaya başlanmıştır.

Gazi Üniversitesi armasını oluşturan mesleki alan simgeleri arma ile birlikte fakülte ayrıcı olarak, her bir diplomanın tasarımında ayrı ayrı yer almıştır. Arma, her yıl 15-20 bin civarında mezun veren Gazi Üniversitesinin diplomalarını 13 yıl boyunca süslemiştir.

Gazi Üniversitesi Armasının kullanıldığı birçok belgede mitolojik kültür değerlerimize de yer verilmiştir. (Şekil: 4)

Üniversite logolarında en fazla kullanılan mitolojik imgelerden biri; atalar kültürü'dür (Çakır, 2013). Bayat'a göre; Milli kütür değerlerimizin temel taşlarından ilkini ve esasını oluşturan mitolojimiz, inanç düzeyinde var olmasıyla güncelliğini korumaktadır. Tarih sahnesine çıkan kavimlerin mitolojisi her kavmin etnik özellikleri ile bağdaşmış durumdadır (Bayat, 2007:11).

Gazi Üniversitesi Arması ile birlikte "Gazi Üniversitesi, Fahri Doktora Belgesi” tasarımında Anka Kuşu bezemesi soyutlanarak yer almıştır. Armanın iki yanında "tuğba" ağacıyla içiçe yorumlanmış tasviri soyutlanmıştır. (Şekil: 7) 
Gazi Üniversitesi Arması, çoğu yerde saç kılı inceliğinde olmak üzere tamamen vektörel formda hazırlanmış (kıymetli kağıt baskı tekniği gibi) klişe-tipografi yöntemiyle baskısı uygulanmıştır.

Böylece, Gazi Üniversitesi'nin yeni diplomaları güvenlik özellikli ilk ve tek diploma özelliğini de kazanmış oldu.

Diplomaların tasarım sürecinde, Gazi Üniversitesi, fakülte, yüksekokul, enstitüler için her biri özgün logolarıyla sembolize edilen lisans diploması, yüksek lisans, doktora diploma tasarımları ve diğer belgelerle birlikte toplam 37 çeşit belge tasarımı hazırlanmış, basılmış ve kullanılmıştır.

Ancak üniversite yönetimi ${ }^{13}$ değişimleri sonrası müdahaleler sonucu diplomanın görsel ve güvenlik unsurları ile ilgili çok önemli özellikler gözden kaçırılmıştır.

$\mathrm{Bu}$ güvenlik özelliği, diploma belgesine güvenlik sağlayan çok önemli bir biyometrik iz olan diplomalarda el yazısıyla isim yazılması işlemiydi. Yani, uzmanı tarafından diploma sahibinin ad ve soyadının el ile kaligrafik olarak yazılması işi idi. Bu yazım işinde, insan elinin diplomada yansıması hem belgeye bir değer katacak, hem de kaligrafi uzmanının biyometrik izi niteliğinde, önemli bir güvenlik özelliğinin diplomalara eklenmesini sağlayacaktı. Bu işlemler tasarım aşamasında düşünülmüş ve ona göre tasarımda güvenlik özellikleri kazandırılmıştı. Hali hazırda yabancı ülke diplomalarının oldukça büyük bir çoğunluğunda, diploma sahibinin ad ve soyadının diploma üzerine islak mürekkeple ve elle yazıldığını görülmektedir. Orijinal el yazması olduğu anlaşılsın diye mürekkebin altındaki taslak olarak yazılmış kurşun kalem izinin dahi silinmediği birçok ünlü üniversitelerin diplomalarında dikkatli inceleme sonucu görülebilmektedir. Gazi Üniversitesi Diplomalarına özgünlük ve güzellik katacak bu uygulamada dönemin yönetimince ne yazık ki göz ardı edildi. Diplomaların verilmeye başlandığında tümünün görsel bütünlüğünü olumsuz olarak etkileyecek ve beğenilmeyen bir yazı fontu kullanıldığ1 görüldü. Bununla birlikte bir büyük hata olarak, diplomalara değer katan "sslak" rektör imzası' da dijital bask1 yöntemiyle diplomalara eklenmiş oldu.

Tasarımın görsel zenginliğini ve güvenlik özelliğini bir anda yok eden bu müdahalenin engellenmesinde tasarımcı etkili olamadı. Tasarımcı tarafından hazırlanan yüz elli civarında baskı kalıbı halinde hazırlanan Gazi Üniversitesinin tüm diploma tasarımları, tasarımcıdan teslim alınarak 2005 yılında basılıp kullanılmaya başlandı. Tasarım sonrası süreçte tasarımcı göz ardı edildi. Aradan geçen 13 yıllık zaman dilimi sonrasında, 2019 yılında Gazi Üniversitesi bölündü, Birçok akademik birimleri yeni kurulan bir başka üniversiteye ${ }^{14}$ aktarıldı. $\mathrm{Bu}$ yeni dönemde Gazi Üniversitesi diploma tasarımlarından "Gazi Arması" çıkarılmış ve farklı bir tasarımla hazırlanan daha sade bir diploma kullanılmaya başlanmıştır.

Diploma belgelerindeki güvenlik riskleri hali hazırda süregelmektedir. Güvenlik özelliği bakımından zaaf taşıyan bir diploma belgesi son derece risklidir. Çünkü bu türdeki diplomalar kopyalanabilir ve sahtesi üretilebilir. Akla gelen sorular şunlardır: Diploma basımı için tasarım orjinalleri ve baskı kalıpları basım sonrası güvenlik altına alınmışmıdır veya imha edilmişmidir..? Basım hizmetleri ne kadar güvenlidir. Aynı diploma bir daha basılsa hangi matbaada basıldığı nasıl anlaşı1ır..? Sahtecilik durumunda kim ne kadar sorumludur...? Sahte diplomanın tespiti kolaymıdır..? Her diploma sahteciliği kolaylıkla ortaya çıkarılabiliyormu..? Diplomalardan sorumlu görevliler bu işle ilgili ne kadar yetki ve sorumluluğa sahip..? Sahtecilik durumunda kim ne kadar sorumlu..? Binlerce diplomay1 imzalarken hiçbir şekilde kontrol etme şansı olmayan yetkili imza sahibi mi..? yoksa basım, yazım ve hazırlık aşamasındaki görevli memurlar mı...? Islak imza neden gerekli..? Arşiv ve elektronik kütügün korunma seviyesi ne ölçüde güvenli..?

Hali hazırda diplomaların büyük çoğunluğunda da bu risk ortadan kaldırılabilmiş değildir.

\footnotetext{
${ }^{13}$ Prof. Dr Kadri Yamaç yönetimi

${ }^{14}$ Ankara Hacı Bayram Veli Üniversitesi
} 
Tüm bu soru işaretlerini ortadan kaldırabilecek, aynı konuda doktora tez ve incelemeli patent, sahibi, tecrübe ile kanıtlanmış profesyonel bir tasarımcı tarafından bu süreçte hazırlanan ve baskı güvenliği özelliği taşıyan diploma tasarımları, üniversite yönetimlerindeki değişimler sonrası idarenin tutum ve yaklaşımlarıyla (tasarımcıdan teslim alındıktan sonra) basım aşaması ve sonrası işlemlerde uygulanmaya konulmamış ve bu güvenlik unsurları diplomalara tam olarak kazandırılmamıştır.

Diplomaların sahtesinin tespiti ve engellenmesi için önerilen, ve tasarımları hazırlanan doktora tezli, bu çok önemli bu uygulama her ne kadar tasarımcısı tarafından önerilmişse de, göz ardı edilmiştir (http://www.acikarsiv.gazi.edu.tr/index.php?menu=2\&secim=10\&YayinBIK=8030).

\section{Sonuç olarak,}

Üniversitelerin kurumsal gücünün göstergesi toplumdaki pozitif algılarıdır. Bu yaklaşımla kurumsallığının görsel unsurlarla desteklenmesi ise son derece önemlidir.

Gazi Üniversitesi Diplomaları önceki haliyle grafik tasarım açısından görsel olarak beğeni görmeyen etkisiz bir tasarımdı. Bu diplomalarda görsel zaafın dışında sahteciliğe karşı güvenlik unsuru yok denecek kadar azdi.

İlk olarak diplomalarda kullanılmak üzere Gazi Üniversitesine bir arma tasarlanmıştır.

Gazi arması bir Şems yorumlamasıdır. "Güneşe ve onun aydınlığına an dolsun” diye başlar Kur'an'da Şems Suresi. Gazi Üniversitesi Arması'nın iki tarafını süsleyen yaprak biçimindeki süs ise bir Anka Kuşu yorumlamasıdır. Doğu Kültüründe Simurg, Batı külüründe Phoenix olarak karşılaştığımız bu mitolojik varlık, bilge ağacında yaşamakta, kendi küllerinden yeniden doğmaktadır. $\mathrm{Bu}$ tasarım bilgelik ve dirilişi temsil etmektedir, tıpkı Cumhuriyetimiz, Gazi Mustafa Kemal ve onun imzası ile Anadolu' da bir meşale gibi yükselen Gazi Üniversitesi gibi...

Gazi Arması, Gazi’nin gücünü yansıtması için düşünüldü. 5 yıllık tasarım sürecinde, Gazi Üniversitesinde kullanılan tüm diplomalar; yıllar süren görsel tasarım, araştırma ve deneysel çalışmalar ve defalarca senato sunumu sonrasında bütünüyle özgün olarak araştırmacı tarafindan yeniden hazırlandı. Diploma güvenliği ve tasarımı araştırmacının doktora tez konusunu oluşturdu. Bu tezin yanısıra, bir adet incelemeli patent, BAP projesi, makale ve teknopark projeside üretildi. Gazi Üniversitesi arması ve diploma görselleri ve güvenlik özellikleri kısıtlıda olsa araştırmacının doktora tezinde yer almıştır.

Gazi Üniversitesi tüm enstitü, fakülte ve yüksek okullar için; her biri özgün logolarıyla sembolize edilen lisans diploması, yüksek lisans ve doktora diploma tasarımları ve diğer belgelerle birlikte toplam 37 çeşit farklı tasarım olarak gerçekleştirilmiştir.

Beş y1llık bir tasarım sürecinde binlerce çalışma içerisinden üretilen Gazi Üniversitesi Armas1 ve onunla bütünleşen Gazi Üniversitesi Diplomalarının görsel etkisi yeterli bulunulmuş, daha detaylı tasarım ve güvenlik özellikleri her ne kadar diploma projesinin özelliklerinde yer almışsa da, dönemin üniversite yönetimi ${ }^{15}$ tarafindan uygulatılmamıştır. Tasarımcının hazırladığı görsel materyaller kendisinden teslim ${ }^{16}$ alınarak bastırılmış ve 13 yıl boyunca da kullanılmıştır.

\footnotetext{
${ }^{15}$ Prof. Dr Kadri Yamaç yönetimi

${ }^{16}$ Gazi Üniversitesi rektörlüğü, 05.07.2005 Tarih, B.30.2.GÜN.0.70.72-18/3007 Sayılı Belge
} 


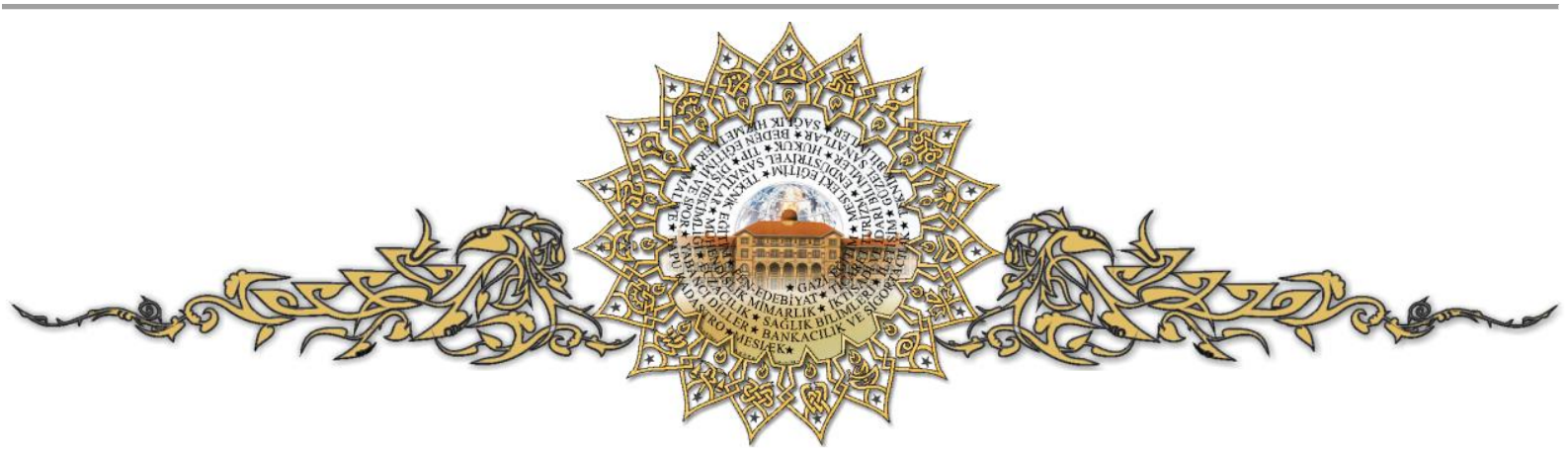

Şekil 4: Gazi Üniversitesi Arması ve kenar dekorasyonu, Ketizmen, A. (2005)

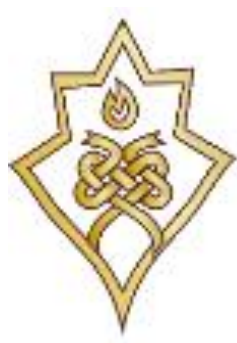

TIP

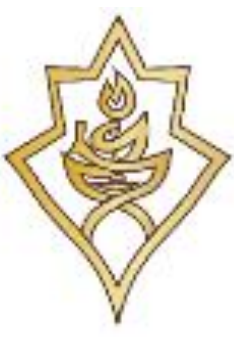

TCZSACIL.IK

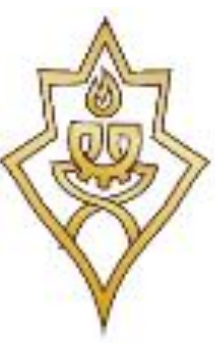

IEKNIK bGil IN-1

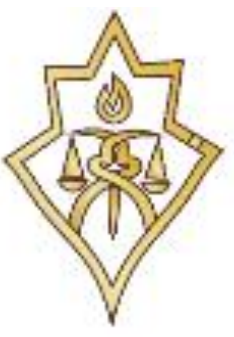

HIIKUK

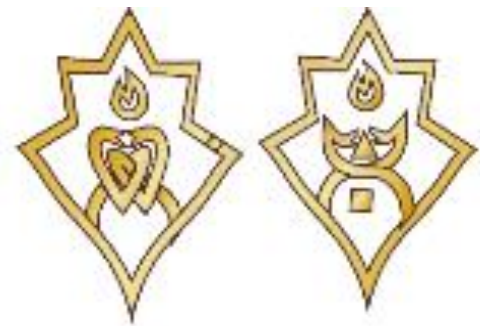

DÇ HFKIR-AI ICit ENDÓSTZIYEL SANATLAR.

Şekil 5: Ketizmen, A. (2005)Gazi Üniversitesi Arma’sını çevreleyen akademik alan simgeleri, (Gazi Üniversitesi rektörlüğü, 05.07.2005 Tarih, B.30.2.GÜN.0.70.72-18/3007 Sayılı Belgesi)

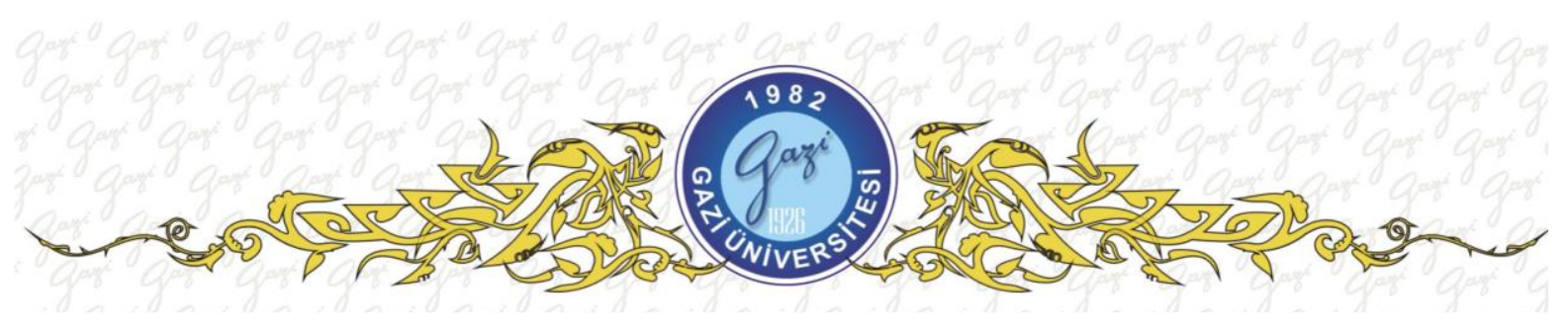

Şekil 6: Gazi Üniversitesi Profesörlük Belgesi için rektörlük binası ile uyumlu Anka kuşu motifinde soyutlanmış tasarım. Ketizmen, A. (2003) 


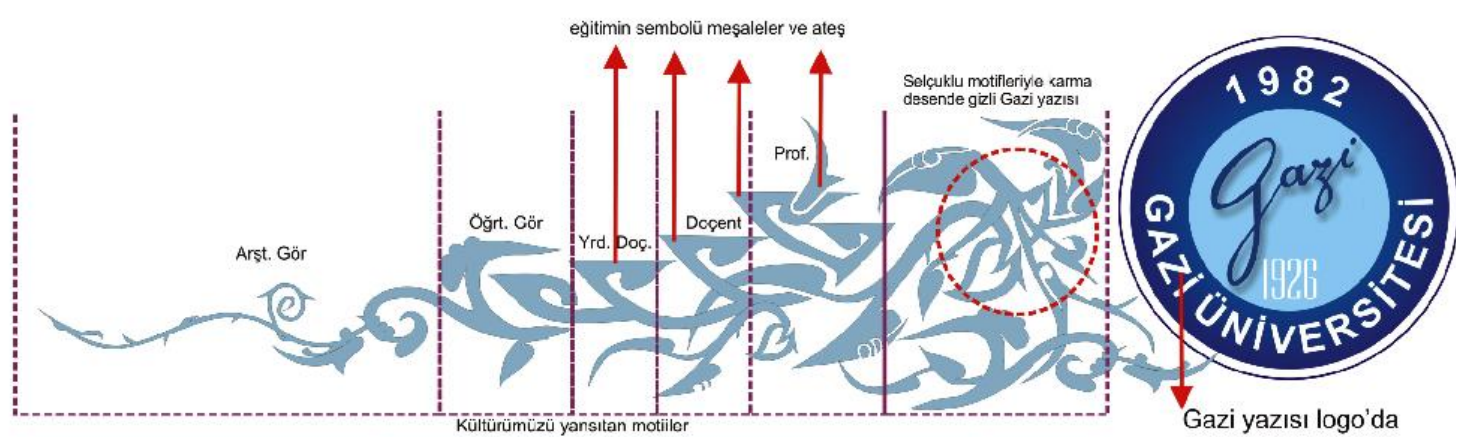

Şekil 7: Gazi Üniversitesi belgelerinde kullanılan bezemenin görsel açılımı Ketizmen, A. (2003)
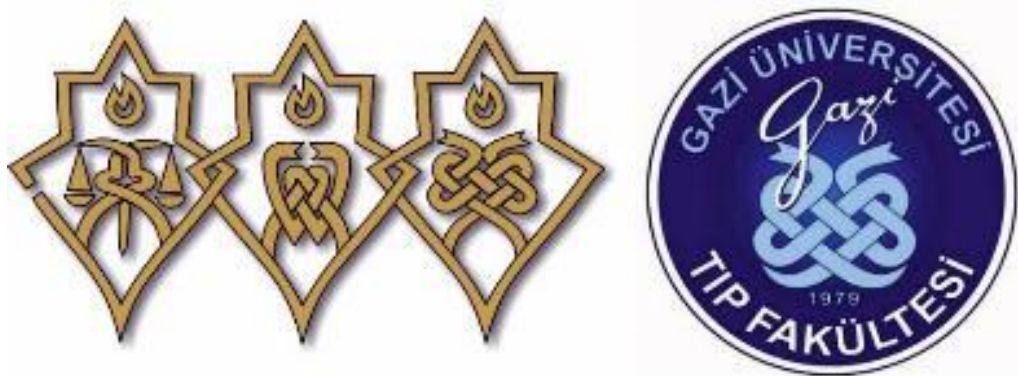

Şekil 8: Gazi Üniversitesi Arması için tasarlanan logo (Gazi tıp Fakültesi logosu olarak ta kullanıldı) Ketizmen, A. (2005) (Gazi Üniversitesi rektörlüğü, 05.07.2005 Tarih, B.30.2.GÜN.0.70.72-18/3007 Say1lı Belge)

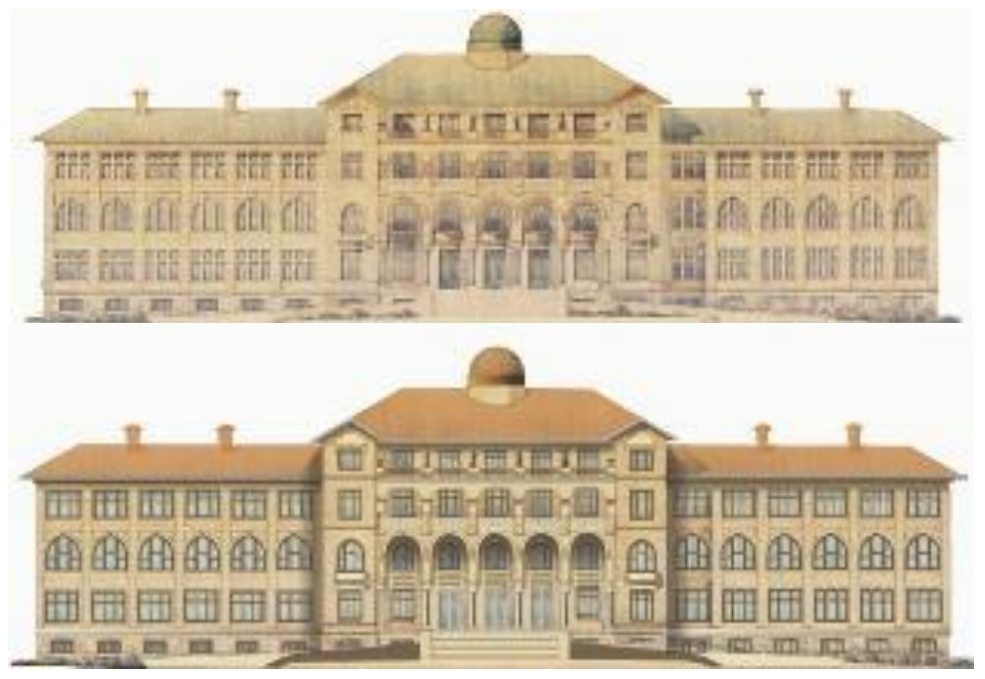

Şekil 9: Gazi Üniversitesi rektörlük binasının (üste) suluboya mimari resminin, gazi forsu için yeniden bilgisayar ortamında yapılan vektörel çizimi (sağda) Ketizmen, A.(2004) (Gazi Üniversitesi rektörlüğü, 2004 Tarih, B.30.2.GÜN.0.00.01.00/M-11016 Say11 Belge) 

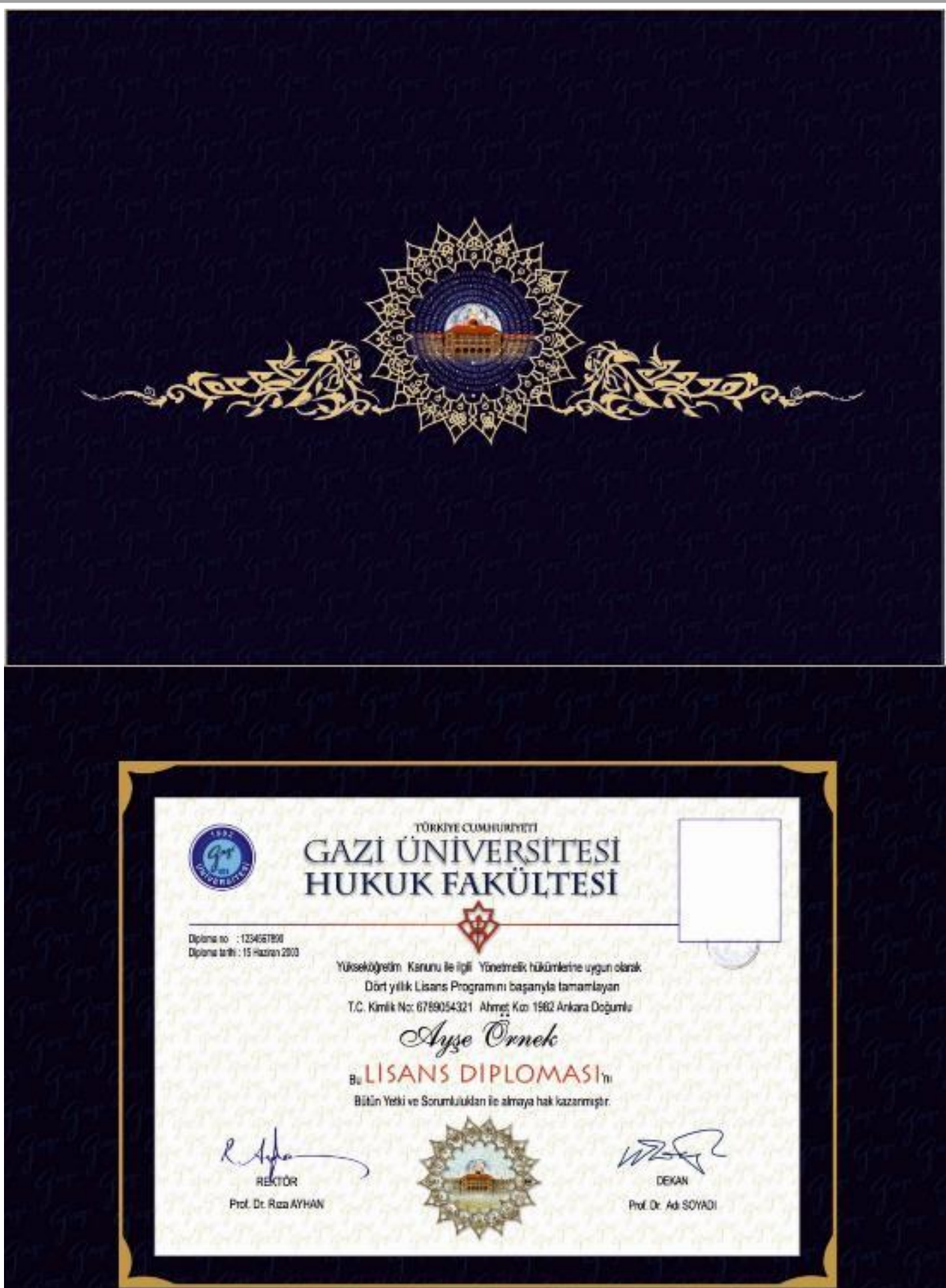

Şekil 10: Abbas Ketizmen Tarafından hazırlanan Gazi Üniversitesi Diploması tasarım örneği. Ketizmen, A. (2003) 


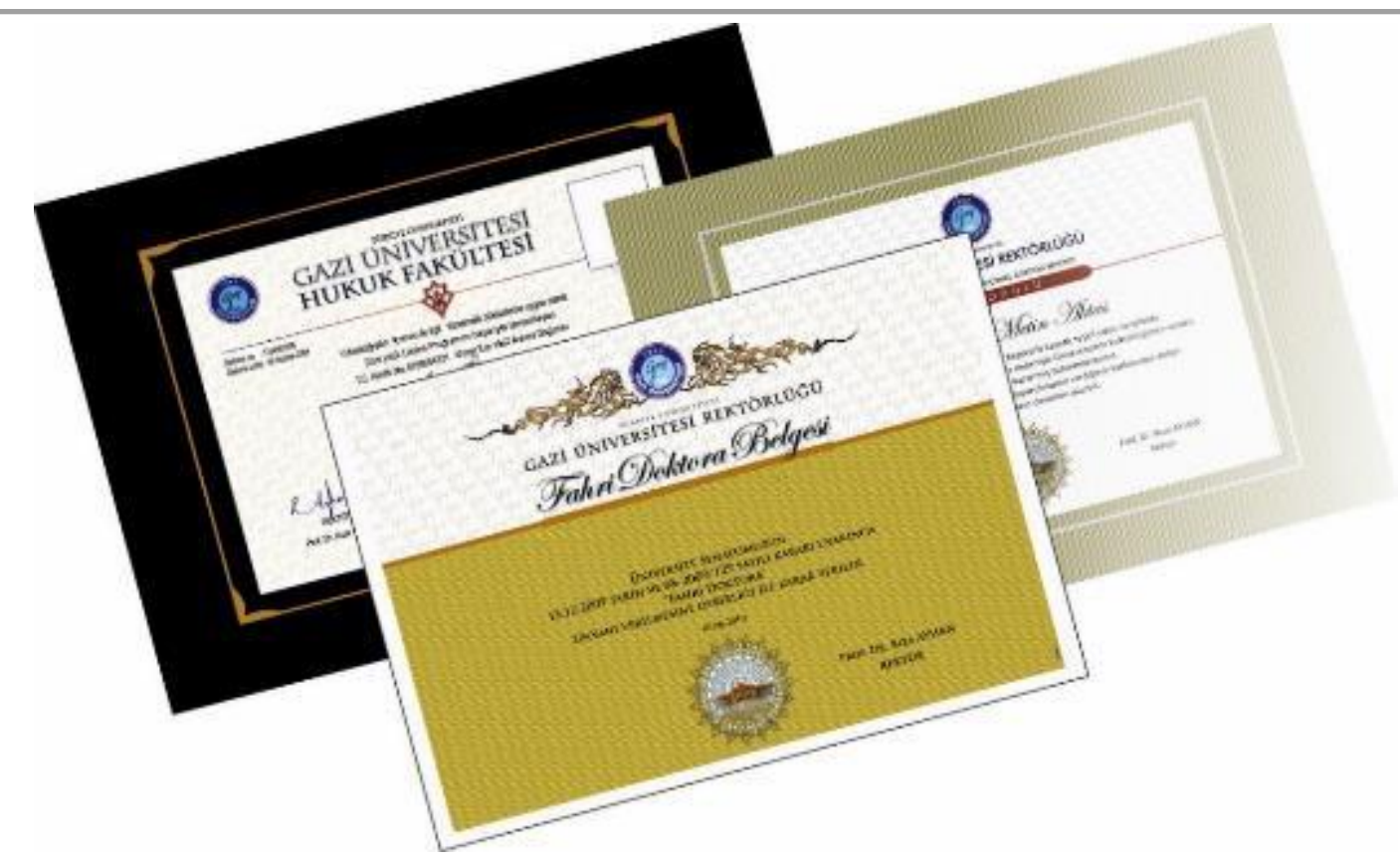

Şekil 11: Gazi Üniversitesi Diploması tasarımlarından seçkiler.

Ketizmen, A. (2003-2007) Gazi Üniversitesi rektörlüğü, 2004 Tarih, B.30.2.GÜN.0.00.01.00/M-11016 Sayıl1 Belgesi ve 19.02.2007 tarihli tutanak

\section{KAYNAKÇA}

Aaker, D. A. (1991). Managing Brand Equity. New York: The Free Press.1991:198

Atasağun, G. (2001)Yahudilikte Dini Sembol ve Kavramlar, Selçuk Üniversitesi, İlahiyat Fakültesi dergisi, X1. Say1, s.126

Bayat, F. (2007). Türk Mitolojik Sistemi 1, "Ontolojik ve Epistemolojik Bağlamda Türk Mitolojisi” Ötüken Yayınları, Ankara, 2007, s.11

Bayraktaroğlu ve Çalış (2010) Amblem ve Logo Tasarımlarında Yalınlaştırmalar, SDÜ ART-E, 201006, s.5-7 (httpsdergipark.org.trdownloadarticle-file193338)

Ceylan, İ.,G.(2015) Amblem ve Logo Tasarımlarında Renklerin Dili, SDÜ ART-E, Kasım Aralık, C 8 Say1.16, s.325 (httpsdergipark.org.trsduarteissue20737221649)

Cumhurbaşkanlığı Arması, (https://www.tccb.gov.tr/cumhurbaskanligi/resmi-simgeler/arma/) Erişim; Nisan 2019

Çakır, E. (2013). Akademik Dünyanın Kentsel İmgelerinden Mitolojik Simgelerine Üniversite Logoları, Milli Folklor Dergisi, 12 (97), ss. 53-69.

Çoroğlu, Ç., (2002).Modern İşletmelerde Pazarlama ve Satış Yöntemi, Alfa Yayınları, İstanbul,2002 s.116

Demir, Ç. (2006). "Markalarda Kurumsal Kimlik Yenileme Kavramı”, Hacettepe Üniversitesi Güzel Sanatlar Fakültesi Sanat Yazıları 14, Onur Matbaacılık, 2006, Ankara. s .49-51

Erhat, A. (1972). Mitoloji Sözlüğ̈̈. İstanbul: Remzi Kitapevi. 
Gazi Üniversitesi Rektörü Enver Hasanoğlu, (http://www.turkcewiki.org/wiki/Enver_Hasano\%C4\%9Flu). erişim; Mart 2019

Gazi Üniversitesi Rektörü Kadri Yamaç, (http://www.turkcewiki.org/wiki/Kadri_Yama\%C3\%A7). erişim; Mart 2019

Gazi Üniversitesi Rektörü Rıza Ayhan, (http://www.turkcewiki.org/wiki/R\%C4\%B1za_Ayhan). erişim; Mart 2019

http://www.acikarsiv.gazi.edu.tr/index.php?menu=2\&secim=10\&YayinBIK=8030 erişim,Nisan 2019)

http://www.underconsideration.com/brandnew/archives/aeg_logo_evolution.jpg.erişim, Haziran 2019)

Ketizmen, A. (2003-2007) Gazi Üniversitesi Rektörlügü, 2004 Tarih, B.30.2.GÜN.0.00.01.00/M-11016 Sayılı Belgesi ve 19.02.2007 tarihli tutanak. (Diploma tasarım ögeleri)

Ketizmen, A. (2008). Sahtecilik ve Tahrifata Karşı Geliştirilmiş Kıymetli Kağıt ve Belgelerin TasarımTeknolojik Özellikleri, Örnek bir Resmi Belge Tasarım Önerisi, Yayınlanmış Doktora Tezi, S. 27, Gazi Üniversitesi, Ankara, Tez No: 293191, Sayfa; 176, 177, (https://tez.yok.gov.tr/UlusalTezMerkezi/tezSorguSonucYeni.jsp). Erişim, Nisan 2019.

Ketizmen, A.(2004) Gazi Üni. Rektörlüğü, 2004 Tarih, B.30.2.GÜN.0.00.01.00/M-11016 Say1lı Belge

Ketizmen, A.(2005) Gazi Üni.Rektörlüğü, 05.07.2005 Tarih, B.30.2.GÜN.0.70.72-18/3007 Sayılı Belge

Öztürk, G.(2006) Logonun Kurum Kimliği Üzerine Etkisi, İstanbul Ticaret Üniversitesi Sosyal Bilimler Dergisi Y11:5 Sayı:9 Bahar 2006/1 s.1-17

(httpacikerisim.ticaret.edu.trxmluihandle11467885\#sthash.ORMgaUuC.0e7mZrtu.dpbs)

Pringle, H.,Thompson, M.(2000) Marka Ruhu, Türkçesi: Zeynep Yelçe - Canan Feyyat, 2000, s.52

Schimmel, A. (1954) "Dinde Sembolün Fonksiyonu Nedir?", A.Ü. \&lâhiyat Fakültesi Dergisi, Ankara, 1954, Cilt: III, Say: 3-4, s.70.

TDK, (2009) http://www.tdk.org.tr/index.php?option=com_gts\&view=gts erişim, Mayıs 2019 